\title{
Antibióticos y acuicultura en Chile: consecuencias para la salud humana y animal
}

\author{
Felipe C. Cabello ${ }^{1}$ \\ Antibiotics and aquaculture in Chile: \\ Implications for human \\ and animal health
}

Industrial antibiotic usage in agribusinesses and aquaculture is the force that drives the evolution of antibiotic resistant bacteria that produce human and animal disease in many countries. Several studies have demonstrated that most of the industrial use of antibiotics is unnecessary, and that modernization and hygienic changes can reduce this use of antibiotics without negative economic impact. In Chile, industrial aquaculture of salmon has expanded rapidly in the last 20 years becoming a major export business. The exponential growth of this industry has been accompanied by an unrestricted heavy usage of antibiotics in the aquatic environments of lakes, rivers and the ocean, and its impact is being felt in the emergence of antibiotic-resistant bacteria around aquaculture sites and a decrease in the plancktonic diversity in the same areas. The passage of antibiotic resistance genes from aquatic bacteria to human and animal pathogens has been demonstrated, indicating that industrial use of antibiotics in aquaculture affects negatively the antibiotic therapy of human and animal bacterial infections. The Chilean situation triggers important concerns because it includes the use of fluoroquinolones in aquaculture, that are not biodegradable and are able to remain in the environment for years as well as being still effective in treating human infections. The use of large volumes of a wide spectrum of antibiotics in an aquatic environment heavily contaminated with human and animal pathogens also amplifies the opportunities for gene transfer among bacteria, facilitating the emergence of antibiotic resistance and more pathogenic bacterial recombinants. The detection of residual antibiotics in salmons marketed for human consumption that can modify the normal flora of the population also suggests the need for controls on this antibiotic usage and on the presence of residual antibiotics in aquaculture food products. This important problem of public health demands an active dialogue between government officials re sponsible for protecting public health, aquaculture industry representatives, politicians, consumers and professionals dealing with these matters (Rev Méd Chile 2004; 132: 1001-6).

(Key Words: Anti-bacterial agents; Aquaculture, Drug resistance, bacterial; Plankton; Salmon)

Recibido el 19 de enero, 2004. Aceptado en versión corregida el 3 de mayo, 2004.

Trabajo presentado parcialmente en una conferencia en la Academia de Medicina, Instituto de Chile, abril 2, 2003.

${ }^{1}$ Miembro correspondiente, Academia Chilena de Medicina y Academia Chilena de Ciencias, Instituto de Chile.

Correspondencia a: Dr. Felipe C. Cabello. Department of Microbiology and Immunology, New York Medical College. Valhalla, NY 10595, EEUU. Teléfono: 914594 4182. Fax: 914594 4176. E mail: cabello@nymc.edu 
$\mathrm{L}$ a ejecución de actividades individuales y colectivas basadas en la racionalidad científica y tecnológica es uno de los atributos que definen a las sociedades modernas ${ }^{1-3}$. La aplicación del concepto microorganístico de la enfermedad, derivado de la obra de Pasteur, Koch y otros, y de la teonía de la evolución de Darwin se encuentra entre los fundamentos que nos ayudan a entender, de manera moderna, la evolución de la enfermedades producidas por agentes vivos en poblaciones humanas y animales $^{1-3}$. El desarrollo del estado democrático, el aumento de los niveles de vida y la profesionalización de los individuos trabajando en estos problemas, han sido fundamentales para aumentar $\mathrm{y}$ extender los éxitos de la sociedad moderna en el manejo y el control de las enfermedades producidas por agentes vivos ${ }^{1-3}$. En Chile se han logrado importantes avances en el manejo y control de las enfermedades infecciosas pero aún persisten problemas serios en la manera en que la sociedad enfrenta algunos de estos problemas, y estas falencias cuestionan las bases modemas y racionales de la sociedad chilena ${ }^{4,5}$. Entre éstos resalta un inadecuado control de la calidad microbiológica del agua y de los alimentos a lo largo del territorio, responsable de la alta incidencia de enfermedades gastrointestinales agudas en todos los grupos etarios ${ }^{4,5}$; una limitada pesquisa epidemiológica por falta de adecuados laboratorios microbiológicos locales a nivel de ciudades, provincias y regiones ${ }^{4,5}$; y la falta de control y desorganización en la venta y el uso de antibióticos y otras drogas empleadas en la prevención y terapia de las enfermedades infecciosas ${ }^{4-6}$. Respecto de este último rubro es importante destacar, por ejemplo, que en Chile se ha restringido el uso de antibióticos en medicina humana desde el año 1998, pero el uso industrial de ellos en la ganadería, en la avicultura, y en la acuicultura permanece totalmente incontrolado (Tabla 1$)^{6,7}$. La escasa información existente indica que en estas industrias probablemente se usan cientos de toneladas de antibióticos anualmente, sobrepasando en volumen este uso industrial a su uso en medicina humana ${ }^{6}$. Por ejemplo, en el país, sin mediar cambios drásticos en la práctica médica y veterinaria que puedan explicarlo, la importación de antibióticos usados en acuicultura como la tetraciclina, el ácido oxolínico, la flumequina y las penicilinas aumentaron entre el año 1990 y el año 1997 de aproximadamente 150 toneladas a 550 toneladas al año ${ }^{6}$. La industria acuícola chilena del salmón usa, para producir una tonelada de salmón, aproximadamente 75 veces más antibióticos que la industria acuícola noruega 6 . El que residuos de antibióticos puedan, además, detectarse en los alimentos producidos por estas industrias y consumidos en el país, sugiere de manera clara que el uso industrial de los antibióticos, y no su uso en medicina humana, es el factor que probablemente más influencia y modula la evolución de la resistencia bacteriana a los antibióticos en Chile ${ }^{6-9}$.

\section{RELEVANCIA Y COSTO DE LA RESISTENCIA BACTERIANA A ANTIBIÓTICOS PARA LA SALUD PÚBLICA}

La aparición de resistencia a antibióticos en bacterias, además de ser un problema biológico, es sin lugar a dudas un problema médico, social, económico y ético dado que las infecciones producidas por estas bacterias resistentes a los antibióticos tienen mayor morbilidad y mortalidad ${ }^{10-14}$. Las proyecciones económicas por días de trabajo perdidos por estas infecciones, por su alta morbilidad y mortali-

Tabla 1. Algunos antibióticos usados en acuicultura en diferentes países

\begin{tabular}{|lccc|}
\hline & \multicolumn{3}{c|}{ País } \\
Antibióticos & Chile & Estados Unidos & Noruega \\
\hline Ácido nalidíxico & + & - & - \\
Ácido oxolínico & + & - & - \\
Amoxacilina & + & - & - \\
Ampicilina & + & - & - \\
Cefotaxima & + & - & - \\
Cloramfenicol & + & - & - \\
Eritromicina & + & - & - \\
Florfenicol & + & - & + \\
Furazolidina & + & - & - \\
Gentamicina & + & - & - \\
Kanamicina & + & - & - \\
Quinolonas & + & - & - \\
Streptomicina & + & - & - \\
Sulfas & + & + & + \\
Tetraciclina & + & + & + \\
Trimetoprim & + & + & + \\
\hline
\end{tabular}

Tabla tomada de la referencia 6 . 
$\operatorname{dad}^{10-14}$, por sus prolongadas hospitalizaciones y porque su tratamiento generalmente requiere del uso de antibióticos más costosos, afectan a toda la sociedad ${ }^{10-14}$. Por ejemplo, en EEUU, la neumonía producida por Staphylococcus aureus resistente al antibiótico meticilina tiene una mortalidad que es 2,5 veces más alta que la neumonía producida por un $\mathrm{S}$ aureus sensible a este antibiótico, su tratamiento necesita de una hospitalización más frecuente, y este tratamiento cuesta aproximadamente $\$ 3.500$ dólares más ${ }^{13}$. Similarmente, las infecciones por Enterobacter resistentes a cefalosporinas de tercera generación se acompañan de un aumento de 30\% en los días de hospitalización, el tratamiento cuesta $\$ 30.000$ dólares más, y duplican su mortalidad de $13 \%$ a $26 \%{ }^{10}$. La Academia de Ciencias de EE.UU. ha estimado que los costos excesivos del tratamiento de las infecciones producidas por bacterias resistentes a los antibióticos en ese país fluctúan entre 150 millones (sin mortalidad) a 3.000 millones de dólares al año si éstas terminan con la muerte del paciente ${ }^{12}$. Un estudio ha demostrado, por ejemplo, que las complicaciones de las peritonitis producidas por bacterias resistentes, como la formación de abscesos y la reoperación, son aproximadamente el doble cuando la terapia antibiótica no es la adecuada para estas bacterias resistentes ${ }^{14}$. El tratamiento antibiótico de bacterias resistentes también genera costos aumentados por la selección de resistencia en la flora normal a antibióticos que son más caros, a veces más tóxicos, y esta resistencia puede, más tarde, ser transmitida a patógenos, aumentando en éstos la resistencia de fondo a estos antibióticos en ciertas áreas geográficas ${ }^{15,16}$. El concepto importante de destacar aquí es que incluso en la terapia antibiótica clínicamente adecuada, el antibiótico selecciona bacterias resistentes en la flora normal del individuo tratado y en su entorno $3,15,16$. En el curso de la terapia, los antibióticos pueden ser aerosolizados y pasar al ambiente a través de la piel y las excretas, incluyendo sudor, orina y deposiciones, conservando en estas excretas su capacidad antibiótica, proyectándose esta actividad antibiótica al entorno, temporal y espacial del paciente tratado con ellos 3,15,16. También se agrega mayor costo al tratamiento de las infecciones producidas por bactenias resistentes porque existen evidencias de que algunas bacterias resistentes serían más patógenas que las bacterias sensibles, produciendo infecciones más severas y más difíciles de tratar, debido a que los mismos elementos genéticos responsables de la resistencia pueden contener genes que, además, aumentan la virulencia bacteriana ${ }^{17}$.

\section{DESARROLLO DEL PROCESO \\ DE RESISTENCIA BACTERIANA A ANTIBIÓTICOS}

El desarmollo del proceso de la resistencia bacteriana a antibióticos es claramente explicado por una síntesis que reúne a la teoría de la evolución de Darwin con el conocimiento de la plasticidad del material genético bacteriano ${ }^{3,16,18}$. Sumariamente, la plasticidad genética de las bacterias con los fenómenos de mutación, intercambio genético y migración genera una diversidad sobre la cual actúa la selección ejercida por la presencia de antibióticos en el ambiente $^{19,20}$. La limitación de espacio impide discutir en este artículo la importante variedad de los mecanismos genéticos usados por las bacterias para modificar su material genético y crear la importante variabilidad que constituye el sustrato sobre el cual actúa la presión selectiva de los antibióticos ${ }^{16,18-22}$. Las evidencias experimentales y epidemiológicas indican claramente que la fuerza motriz del proceso evolutivo hacia la resistencia bacteriana a antibióticos es el uso y consumo de estas substancias farmacológicas y sin este consumo y la presencia de estas substancias en el ambiente la resistencia bacteriana dejańa de existir,16,23,24. El rol motriz del uso y el consumo de antibióticos en la evolución de la resistencia bacteriana a ellos está también demostrado por el hecho de que en cada oportunidad en que ha habido una restricción del uso de antibióticos el fenómeno de la resistencia ha disminuido $3,16,23$, y esto ha sucedido a nivel individual y colectivo, incluyendo individuos sanos y enfermos, hospitales, criaderos, granjas, ciudades y países $3,16,23$. Los mecanismos genéticos responsables de la evolución de la resistencia a antibióticos son inherentes al material viviente, de manera que -en principio- son inmodificables ${ }^{16,18}$, de tal modo que la única intervención posible sobre este fenómeno evolutivo es la modificación del uso y del consumo de antibióti$\cos ^{3,16,23,24}$. La modificación del uso y del consumo de antibióticos a niveles capaces de influir en la evolución de la resistencia a los antibióticos ha sido lograda en Canadá, EE.UU. y en países europeos, con una mezcla de medidas educativas, restricciones legales y un continuo diálogo e intercambio entre 
los estamentos científicos, políticos, industriales y de consumidores para investigar rutas destinadas a modificar el uso y el consumo innecesario de antibióticos en diversas actividades 3,16,23,24.

\section{Uso de ANTiBióticos EN ACUicultuRA, EN CHILE}

La acuicultura es una actividad industrial relativamente nueva y en ella, al igual que en la ganadería y en la avicultura, el empleo de antibióticos como profilácticos es probablemente lo que comanda su consumo y uso en la industria ${ }^{6,8,9,25}$. El uso profiláctico de antibióticos en todas estas industrias está dirigido a prevenir infecciones en poblaciones de animales altamente susceptibles a la infección debido a perturbaciones inmunológicas producidas por el hacinamiento, las manipulaciones y problemas dietéticos creados por su crianza en un sistema industrial $8,9,24,26$. Estudios recientes han mostrado claramente que tanto en ganadería como en acuicultura el uso profiláctico de antibióticos puede ser reemplazado por medidas de higiene, sin repercusiones para la salud animal y la economía de la industria, demostrando que este uso profiláctico de antibióticos es innecesario y totalmente prescindible 2,16,24,26. Está también demostrado que el uso de antibióticos en acuicultura genera la aparición de bacterias resistentes a los antibióticos en los entornos acuáticos donde se desarrolla esta actividad ${ }^{17,26-}$ 29 , y existen evidencias epidemiológicas y moleculares, señalando que los genes que median esta resistencia pueden ser transmitidos de bacterias acuáticas a bacterias capaces de producir infecciones en humanos y en animales terrestres ${ }^{17,26-29}$. Esto demuestra que los compartimientos acuáticos y terrestres carecen de fronteras respecto del flujo de genes de resistencia a antibióticos ${ }^{26-29}$, y también que el fenómeno de resistencia es un fenómeno global, ya que el uso de antibióticos en un ambiente tendrá, a lo largo del tiempo, repencusiones en otros ambientes aparentemente lejanos 3,5,16,27,29. En Chile, el uso de antibióticos en acuicultura se acompaña además, de una serie de características propias de esta actividad en el país y que incluyen, por ejemplo, el uso ilimitado de antibióticos utilizados en medicina humana, como las fluoroquinolonas, los cuales permanecen en el ambiente por tiempos prolongados con su capacidad antibiótica intacta, ya que no son biodegradables (Tabla 1) ${ }^{6,30}$. El uso de las fluoroquinolonas en acuicultura en Chile crea las condiciones para generar problemas de resistencia a substancias antibacterianas altamente efectivas y útiles en medicina humana ${ }^{6}$, y es por esta razón que el uso veterinario de ellas en profilaxis está totalmente proscrito en otros países (Tabla 1)3,6,16. El país carece de un programa de seguridad alimentaria que garantice la ausencia de antibióticos residuales en la carne de salmón y otros productos acuícolas ${ }^{6}$ y no es aventurado especular que partidas de este producto que no pueden ser comercializadas en el extranjero por su alto contenido de antibióticos residuales son comercializadas en el país, alterando la flora intestinal normal de la población y produciendo potenciales efectos tóxicos ${ }^{3,16}$. La documentada e importante contaminación del litoral chileno y de las aguas de ríos y lagos con los más variados patógenos bacterianos humanos y animales ${ }^{31-36}$, incluyendo varios resistentes a los antibióticos, crea junto con el uso de antibióticos en acuicultura en estos ambientes, las condiciones ideales para el libre flujo de la información genética que codifica esta resistencia entre diferentes bacterias de estos ambientes y patógenos humanos y de animales terrestres ${ }^{19,31-36}$. Las deficiencias sanitarias respecto de la calidad del agua de bebida y de la disposición de excretas en las regiones con industria acuícola, como la X Región, facilitan también el tráfico de bacterias entre diversos nichos ecológicos y el flujo de información genética entre ellas, incluyendo la de genes para la resistencia a antibióticos y de virulencia bacteriana ${ }^{6,16,19,25}$. La industria acuícola, a través del uso de antibióticos y de los procesos de alteración de la microbiota ambiental producidos por sus desechos orgánicos en los ambientes acuáticos (eutrofización), genera también cambios drásticos en el plancton de estos ambientes 37,38 , y estos cambios pueden potencialmente favorecer el flujo de información genética entre diversas especies bacterianas presentes en ellos, facilitando la aparición de bacterias resistentes a los antibióticos ${ }^{37,38}$. El traslado de peces de ambientes de agua dulce como lagos y ríos a ambientes marinos, crea también las condiciones para la migración de bacterias resistentes a los antibióticos entre estos ambientes ${ }^{16,37,38}$, y facilitan la diseminación de estas bacterias entre nichos ecológicos geográficamente lejanos $3,16,37,38$. El uso de toneladas de antibióticos en la industria acuícola probablemente expone también al personal que trabaja en ella, a sus grupos familiares y a sus 
comunidades a la actividad antibiótica de estas substancias, creando en sus intestinos, piel, faringe y genitales alteraciones de la flora bacteriana normal que favorecen la aparición y la diseminación de bacterias resistentes a los antibióticos y la infección con bacterias patógenas ${ }^{3,16}$. El uso excesivo de antibióticos en acuicultura se puede acompañar de la selección de patógenos de peces resistentes a los antibióticos que ocasionalmente pueden también infectar a humanos, y que incluyen bacterias tales como Aeromonas, Vibrios y el Streptoccocus iniae ${ }^{39}$.

\section{ConCLUSIONES}

Pareciera indiscutible que el uso masivo de antibióticos en la acuicultura genera una serie de repercusiones que escapan los confines geográficos y económicos de esta actividad, y que tienen la capacidad de influenciar negativamente aspectos de la salud humana y animal. El hecho que el uso de antibióticos en medicina humana se haya restringido desde hace 6 años en Chile y, sin embargo, el que su uso en actividades industriales como la acuicultura permanezca incontrolado en el país, a la luz de este somero análisis pareciera reflejar una incoherencia

\section{REFERENCIAS}

1. WinsLow CEA. The conquest of epidemic disease. A chapter in the history of ideas. Madison University of Wisconsin Press, Madison, WI, 1980.

2. DowLng HF. Fighting infection. Conquests of the Twentieth Century. Harvard University Press. Cambridge. MA, 2000.

3. Shnayerson M, Plotkin MJ. The killers within. The deadly rise of drug-resistant bacteria. Back Bay Books. Little, Brown and Co., Boston, MA, 2002.

4. WolfF M. Changes in the epidemiology of infectious diseases in Chile: 1990-2000. Rev Méd Chile 2002; 130: 353-62.

5. Caвeшo FC, Ciaude M. Changes in the epidemiology of infectious disease in Chile: 1990-2000. Rev Méd Chile 2002; 130: 1185-7.

6. САВЕLO FC. Antibióticos y acuicultura. Un análisis de sus potenciales impactos para el medio ambiente y la salud humana y animal en Chile. Análisis de Políticas Públicas. Organización Terram, Publicación № 17, 2003. tecnológica, económica y política de relevancia. Una comprensión cabal de la teoría de la evolución y de la teoría microorganística de las enfermedades infecciosas indica que el uso excesivo de antibióticos en cualquier nicho ecológico manifestará sus efectos deletéreos sobre la salud humana en el mismo nicho y en nichos alternativos y lejanos. Podríamos postular que la incoherencia que se advierte en las políticas del uso y del manejo de los antibióticos en Chile en diversas actividades, es el resultado de un desconocimiento científico básico, de una falta de profesionalización de las actividades en este campo, y de las limitaciones de la democracia, que impiden que profesionales, consumidores y otros individuos afectados por ellas puedan ejercer las adecuadas influencias políticas para modificarlas, de acuerdo con los cánones modernos del conocimiento científico y tecnológico. Pareciera que, al igual que en otras latitudes, la solución a este problema pasará por un amplio y activo debate que incluya científicos, consumidores, personeros de gobierno encargados de velar por la salud de la población y de la calidad de los alimentos, representantes de la industria acuícola y los políticos. Esperamos que esta breve revisión en la Revista sirva para estimular esta atrasada, pero necesaria y urgente discusión.

7. BaVESTRELO L, CABELO QFA. Chile enforces regulations on the sale and dispensing of antibiotics. APUA Newslett 2001; 19: 5.

8. ANGULO F. Antimicrobial agents in aquaculture: Potential impact on public health. APUA Newslett 2000; 18: 1,4-5.

9. Alderman DJ, Hastings TS. Antibiotic use in aquaculture: development of antibiotic resistance, potential for consumer health risks. Int J Food Sci Technol 1998; 33: 139-55.

10. Cosgrove SE, Saye KS, Eliopoulos GM, Carmel Y. Health and economic outcomes of the emergence of third generation cephalosporin resistance in Enterobacter species. Arch Intern Med 2002; 162: 185-90.

12. HARRISON PF, LEDERBERG J. Antimicrobial Resistance: Issues and Options. Workshop Report. National Academy Press, Washington, DC, 1998.

13. Rubin RJ, Harrington CA, Poon A, Dietrich K, Greebe JA, Moiduddin A. The economic impact of Staphyloccocus aureus infection in New York City hospitals. Emerg Infect Dis 1999; 5: 9-17. 
14. Mosdell DM, Morris DM, Voltura A, Pitcher DE, TwIEST MW, Milne RL et aL. Antibiotic treatment for surgical peritonitis. Ann Surg 1991; 214: 543-9.

15. LevY SB. Antibiotic resistance: Consequences of inaction. Clin Infect Dis 2001; 33 (Suppl 3): S124S129.

16. LeVY SB. The antibiotic paradox. Perseus Publishing. Cambridge, MA, 2001.

17. Aguero ME, DeLuca AG, Timmis KN, Cabelo FC. A plasmid-encoded outer membrane protein, TraT, enhances resistance of Escherichia coli to phagocytosis. Infect Immun 1984; 46: 740-6.

18. Courvalin P, Trieu-Cuot P. Minimizing potential resistance: The molecular view. Clin Infect Dis 2001; 33 (Suppl 3): S138-S146.

19. Bushman F. (Ed.) Lateral DNA Transfer. Mechanisms and Consequences. Cold Spring Harbor Laboratory Press, Cold Spring Harbor, New York, 2002.

20. Atlas RM, Bartha R. Microbial Ecology. Fundamentals and Applications. Addison Wesley Longman. Menlo Park. CA, 1998.

21. Caвello F, Silva AB. Resistencia bacteriana a antibióticos mediante herencia extracromosómica. Rev Méd Chile 1972; 101: 216-22.

22. González G, Sossa K, Beшo H, Domínquez M, MeLa $\mathrm{S}$, Zemelman R. Presence of integrons in isolates of different biotypes of Acinetobacter baumannii from Chilean hospitals. FEMS Microbiol Lett 1998; 161: 125-8.

23. TEUBER M. Veterinary use and antibiotic resistance. Curr Opin Microbiol 2001; 4: 493-9.

24. Gorbach SL. Antimicrobial use in animal feed. Time to stop. N Engl J Med 2001; 345: 1202-3.

25. Goldberg RJ, EuJotT MS, NayLor RL Marine Aquaculture in the United States. Environmental Impacts and Policy Options. Pew Oceans Commission. Arlington, Virginia. 2001; 1-33.

26. Sorum H, L'AbeE-Lund TM. Antibiotic resistance in food related bacteria, a result of interfering with the global web of bacterial genetics. Int J Food Microbiol 2002; 78: 43-56.

27. Sorum H. Mobile drug resistance genes among fish bacteria. APMIS 1998; 106 (Suppl 84): S74-S76.

28. Schmidt AS, Bruun MS, Dalsgaard I, LaRsen JL. Incidence, distribution, and spread of tetracycline resistance determinants and integron associated antibiotic resistance genes among motile aeromonads from a fish farming environment. Appl Environ Microbiol 2001; 67: 5675-82.
29. Rhodes G, Huys G, Swings J, Mc Gann P, Hiney M, SMTth P ET AL. Distribution of oxytetracycline resistance plasmids between aeromonads in hospital and aquaculture environments: Implication of Tn1721 in dissemination of the tetracycline resistance determinant Tet A. Appl Environ Microbiol 2000; 66: 3883-90.

30. Hektoen H, Berg JA, Hormazábal V, Yndestad M. Persistence of antibacterial agents in marine sediments. Aquaculture 1995; 133: 175-84.

31. Martínez M, Mondaca MA, Zemelman R. Antibiotic resistant gram negative bacilli in the sewage of the city of Concepcion, Chile. Rev Latinoam Microbiol 1994; 36: 39-46.

32. Miranda CD, CASTILO G. Resistance to antibiotic and heavy metals of motile aeromonads from Chilean freshwater. Sci Total Environ 1998; 224: 167-76.

33. Miranda CD, Zemelman R. Antibiotic resistant bacteria in fish from the Concepcion Bay, Chile. Marine Poll Bul 2001; 42: 1096-102.

34. Miranda CD, ZeMELMAN R Antimicrobial multiresistance in bacteria isolated from freshwater Chilean salmon farms. Sci Total Environ 2002; 293: 207-18.

35. Montoya R, Domínguez M, González C, Mondaca MA, ZeMELMAN R. Susceptibility to antimicrobial agents and plasmid carrying in Aeromonas hydrophila isolated from two estuarine systems. Microbios 1992; 69: 181-9.

36. Silva J, Zemelman R, Mondaca MA, Henríquez M, Merino C, González C. Antibiotic resistant gram negative bacilli isolated from sea water and shellfish. Possible epidemiological implications. Rev Latinoam Microbiol 1987; 29: 165-9.

37. Bushman A. Impactos de la acuicultura: El estado del conocimiento en Chile y el mundo. Terram Publicaciones, Santiago, Chile, 2001.

38. Bushman A, Pizarro R. El costo ambiental de la salmonicultura en Chile. Terram Publicaciones (2001). Análisis de Políticas Públicas - № 5, 2001.

39. Weinstein MR, Litt M, Kertesz DA, Wyper P, Rose D, Coulter M ET AL. Invasive infections due to a fish pathogen, Streptococcus iniae. N Engl J Med 1997; 337: 589-94.

\section{Agradecimientos}

El autor agradece a la John Simon Guggenheim Memorial Foundation, por el otorgamiento de una beca EE.UU. - Canadá 2004, para estudiar las repercusión en la salud pública del uso de antibióticos en acuicultura. 